\title{
Desain prototipe aplikasi sistem monitoring browser ponsel anak untuk menerapkan internet sehat dengan kontrol orang tua
}

\author{
Taufik Hidayat ${ }^{1}$, Mansur ${ }^{2}$, Rahmah $^{3}$ \\ ${ }^{1,2,3}$ Program Studi Teknik Informatika Jurusan Teknik Informatika Politeknik Negeri Bengkalis \\ Jln. Bhatin Alam Sungai Alam, Bengkalis, Riau, Telp. (+62766) 7008877 \\ e-mail: ${ }^{1}$ taufik.developer@gmail.com, ${ }^{2}$ mansur.polbeng82@gmail.com, \\ rahmahh03@gmail.com
}

\begin{abstract}
Abstrak
Penggunaan internet dikalangan anak-anak saat ini sudah menjadi trend, bahkan banyak orang tua sudah memberikan ponsel android kepada anak-anak dalam melakukan komunikasi sehari-hari. Hal tersebut sangat berdampak kepada anak dalam pemanfaatan teknologi internet yang kurang sehat seperti mendapatkan data dan informasi melalui browsing internet tanpa pemantauan orang tua sehingga anak dengan mudah mendapatkan kata-kata atau informasi yang tidak layak dikonsumsi oleh anak tersebut. Penelitian ini bertujuan untuk mendesain aplikasi sistem monitoring browser ponsel anak untuk menerapkan internet sehat dengan kontrol orang tua menggunakan metode prototipe. Hasil penelitian tersebut berupa rancangan aplikasi monitoring broser anak yang dapat digunakan untuk memantau aktivitas browsing internet pada ponsel anak secara online pada platform android dengan otomatis mengirim pesan notifikasi kepada orang tua dan orang tua dapat memberikan respon atau balasan secara langsung ketika anak sedang mencoba melakukan aktivitas browsing internet yang tidak sehat.
\end{abstract}

Kata kunci: Kontrol orang tua, penelusuran aman, sistem monitoring, aktivitas penelusuran harian

\begin{abstract}
The use of the internet among children currently have become a trend, even many parents already gives android phones to children in doing everyday communication. It is so impacting to the child in the utilization of internet technologies that are less healthy as get data and information through browsing the internet without monitoring parents so children easily get words or information that is not feasible is consumed by the child. This research aims to design a monitoring system of the mobile browser app to implement a healthy internet parental control method using prototype. The results of such research in the form of a draft application monitoring these children which can be used to monitor the activities of internet browsing on mobile child online on the android platform with automatic notification to send a message to parents and parents can give a response or reply directly when the child was trying to do internet browsing activity that is not healthy.
\end{abstract}

Keywords: Parental Control, Safe Browsing, Monitoring System, Daily Browser Activity.

\section{Pendahuluan}

Teknologi informasi da komunikasi semakin berkembang, termasuk teknologi komunikasi jaringan wireless yang menyebabkan evolusi suatu perangkat menjadi canggih, salah satunya perangkat mobile berbasis sistem operasi android [6]. Perangkat mobile yang 
menggunakan android sudah berkembang pesat di kehidupan masyarakat, tidak hanya digunakan untuk melakukan telekomunikasi. Namun digunakan sebagai sarana untuk mencari berbagai informasi melalui internet [7].

Berdasarkan survei We Are Social's compendium of world digital stats untuk estimasi pada Januari 2016, Indonesia kini memiliki 88.100.000 pengguna internet aktif, naik 15\% selama 12 bulan terakhir, dan $85 \%$ dari populasi tersebut memiliki perangkat mobile, sementara 43\% memiliki smartphone. Selanjutnya, sebagian besar masyarakat Indonesia sekarang berkisar antara $43 \%$ sampai $70 \%$ mengakses internet menggunakan perangkat mobile [5].

Pada masa sekarang informasi yang tersedia di internet dapat di akses dengan cepat dan mudah melalui smartphone. Dari anak-anak sampai dengan orang dewasa dapat dengan bebas mengakses internet, informasi yang ditawarkan internet tersedia dalam banyak konten, mulai dari konten yang bersifat umum maupun tidak. Pengguna internet Indonesia didominasi oleh anak-anak dan remaja yang menggunakan smartphone mereka untuk mengakses internet baik untuk mencari data atau informasi seperti tugas-tugas sekolah, bersosial media, forum diskusi, dan lain sebagainya yang belum tentu informasi atau konten yang di akses sesuai dan aman untuk masyarakat [2] terutama anak dan para remaja. Hal ini terbukti dari hasil survei APIJII tahun 2016 yang memaparkan bahwa 76,4\% pendapat pengguna terhadap keamanan berinternet bagi anak adalah tidak aman [1].

Sementara itu, orang tua tidak dapat mengetahui dan memantau sepenuhnya aktivitas yang dilakukan oleh anaknya saat browsing internet. Padahal, pengawasan orang tua terhadap anak sangat diperlukan guna menghindari resiko yang tentunya tidak diharapkan bagi setiap orang tua [4].

Penelitian tentang "Mobile Activity Monitoring System Using Android Spy" mengatakan pada zaman sekarang ponsel android sudah berada dimana saja yang sudah pasti ponsel Android digunakan untuk banyak aktivitas. Salah satu yang menggunakannya adalah termasuk anak. Sehingga perlu adanya tracking baik itu lokasi ataupun data SMS/Telpon dari ponsel anak agar mendapatkan pengawasan dari ancaman luar yang bisa saja mungkin terjadi [3][10]. Selain itu, untuk memantau dan mengendalikan data supaya terhindar dari penyalahgunaan informasi data pivasi maka perlu aplikasi opensource yang berfungsi secara real time dalam memberikan informasi terhadap ancaman internet berupa data dan informasi yang kurang sehat [11].

Oleh karena itu, perlu dibuat sebuah aplikasi sistem monitoring browser ponsel anak untuk menerapkan internet sehat dengan kontrol orang tua melalui android dan diberi nama SMiP Track yang mana pada sistem ini, data history browser ponsel anak akan dilakukan tracking. Sehingga, orang tua dapat memantau dan mengontrol setiap aktivitas browsing internet yang dilakukan oleh anak. SMiP Track merupakan aplikasi monitoring pada perangkat mobile yang dapat melacak setiap aktivitas browsing internet yang dilakukan anak melalui smartphone. Apabila anak mencoba melakukan browsing yang dianggap tidak baik, maka aplikasi secara otomatis akan mengirim pesan notifikasi kepada orang tua. Kemudian orang tua dapat memberikan respon atau balasan secara langsung jika anaknya sedang mencoba melakukan aktivitas browsing internet yang tidak sehat. Aplikasi ini menghasilkan informasi tetang aktivitas browsing internet yang dilakukan oleh anak dan diharapkan mampu memberi kemudahan kepada orang tua dalam memantau setiap aktivitas browsing internet anak, mengurangi tingkat pengaksesan konten yang berbau negatif pada anak saat menggunakan fasilitas internet, dan mendorong setiap anak agar selalu waspada dalam mengakses kontenkonten yang tersedia diinternet.

\section{Metode Penelitian}

Adapun tahapan yang digunakan dalam pelaksanaan penelitian ini yaitu menggunakan model prototipe sebagai pengembangan sistem. Beberapa tahapan untuk melakukan desain aplikasi sistem monitoring browser ponsel anak dapat dilihat di Gambar 1. 


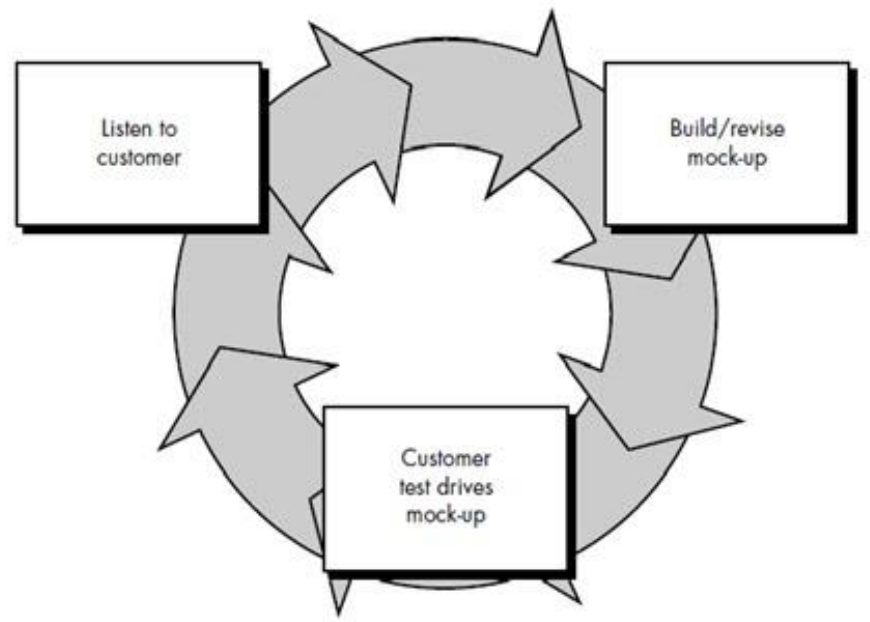

Gambar 1. Prototype method model [8], [9]

\subsection{Listen to Customer}

Tahapan ini bertujuan untuk mengetahui keluhan masyarakat sehingga peneliti dapat memahami keinginan dari masyarakat. Sebagai data pendukung, perlu dilakukan pengumpulan data. Ada 2 metode yang digunakan dalam pengumpulan data, diantaranya:

a. Observasi; pada tahap ini peneliti mengamati langsung masalah yang berkaitan tentang penggunaan ponsel yang berhubungan tentang pemanfaatan internet pada anak dalam aktivitas sehari-hari ataupun kegiatan mereka pada jam bersantai.

b. Studi Pustaka; pada tahap ini peneliti mencari informasi yang berkaitan dengan penjadwalan pribadi baik melalui jurnal, artikel, prosiding, buku dan referensi lain yang bersumber dari internet.

\subsection{Build/Resive Mock-Up}

Tahapan ini dimulai dari perancangan sistem yang akan dibangun sampai ketahapan pembuatan sistem dan program aplikasi. Adapun tahapan untuk membangun / build sistem ini adalah sebagai berikut:

\subsubsection{Rekayasa dan pemodelan sistem}

Langkah pertama dalam melakukan perancangan sistem ini dimulai dengan membangun keseluruhan elemen sistem. Dalam melakukan rekasa, terdapat sumber daya yang akan dibutuhkan, terutama sumber daya perangkat lunak pendukung kebutuhan. Berkut daftar perangkat lunak yang digunakan, dapat dilihat pada Tabel 1 .

Tabel 1. Daftar perangkat lunak yang digunakan

\begin{tabular}{ll}
\hline \multicolumn{1}{c}{ Nama } & \multicolumn{1}{c}{ Keterangan } \\
\hline \multirow{2}{*}{ Android Studio } & $\begin{array}{l}\text { Merupakan IDE untuk mengembangkan } \\
\text { aplikasi android secara native dengan } \\
\text { dukungan bahasa pemograman Java }\end{array}$ \\
Microsoft Azure Cloud Service & $\begin{array}{l}\text { Server untuk hosting file-file PHP yang } \\
\text { nantinya akan di akses oleh sistem }\end{array}$
\end{tabular}

FileZilla

Digunakan sebagai tools transfer file ke 


$\begin{array}{ll} & \text { server } \\ \text { PHP5.6 } & \text { Versi platform PHP yang digunakan oleh } \\ & \text { server dengan dukungan pemograman PHP } \\ & \text { Media tempat penyimpanan data-data yang } \\ \text { MySQL nanti diperlukan oleh sistem } & \\ & \text { (JavaScript Object Notation) format untuk } \\ \text { pertukaran data yang nantinya } & \text { menjembatani antara server dan aplikasi } \\ \text { android. }\end{array}$

\subsubsection{Desain user interface sistem monitoring browser ponsel anak}

Pada proses desain, dilakukan representasi interface / UI yang dapat diperkirakan sebelum dibuatnya proses pengkodean. Adapun desain UI aplikasi dapat dilihat pada Gambar 2,3 dan 4:
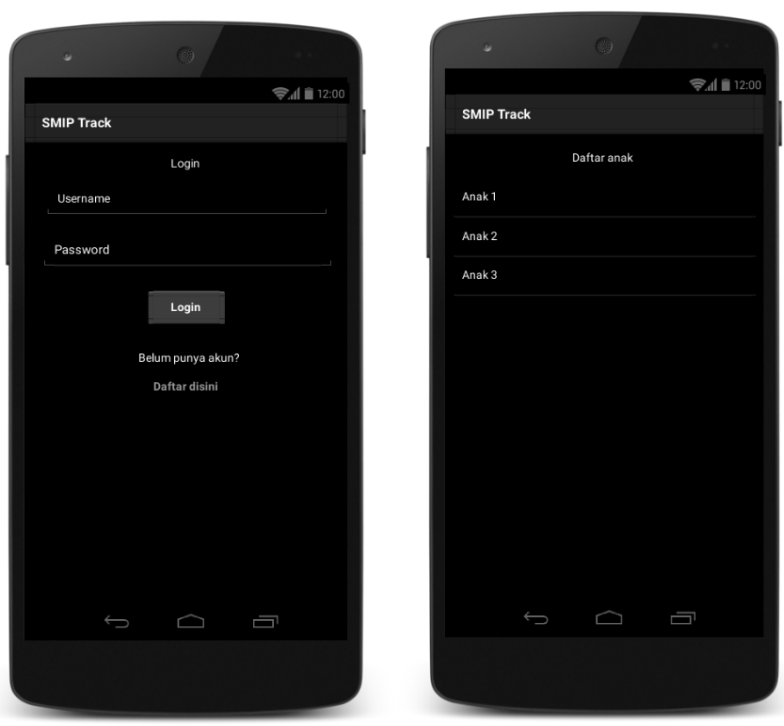

Gambar 2. Tampilan login dan tampilan pilih anak 

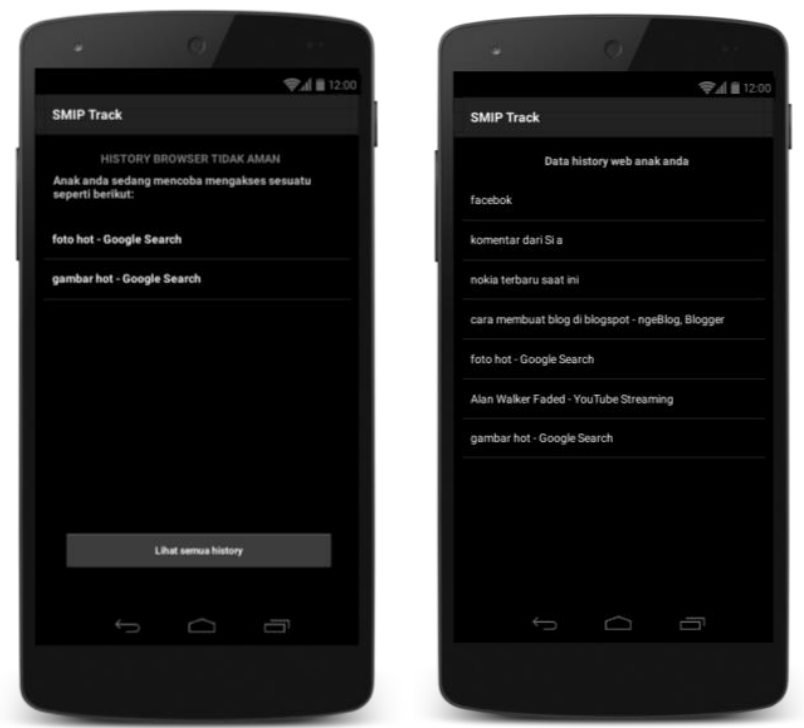

Gambar 3. Tampilan filter history dan melihat semua history browser anak
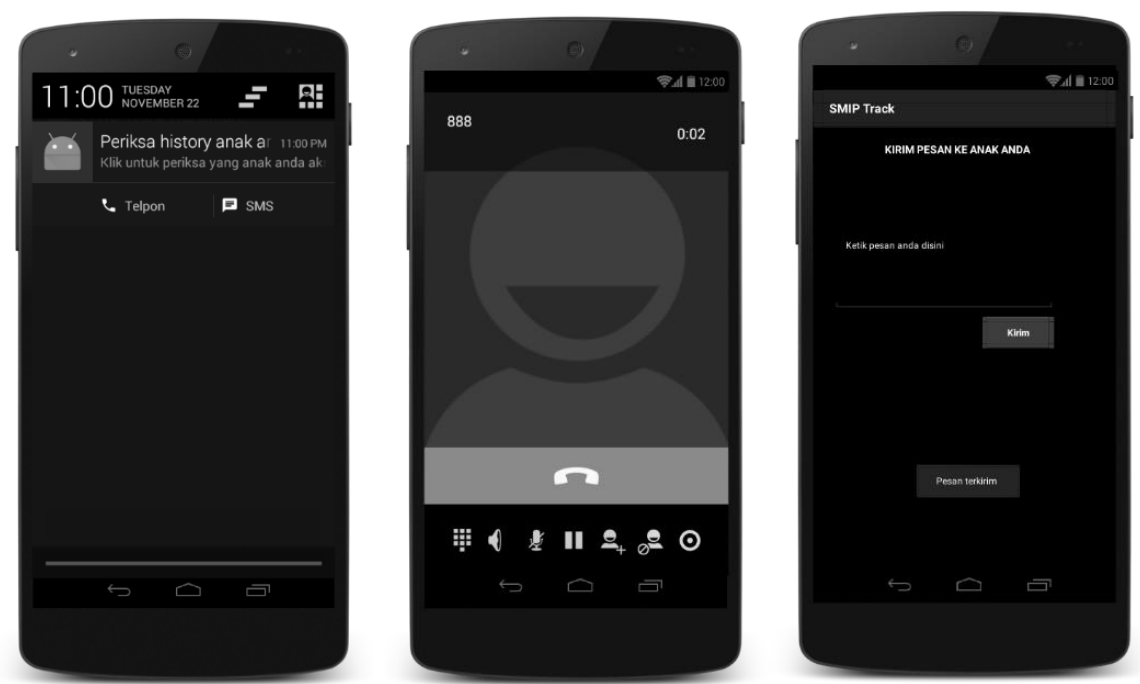

Gambar 4. Tampilan notifikasi, aksi telepon dan aksi SMS

\subsubsection{Pengkodean}

Pengkodean dilakukan menggunakan IDE Android Studio dengan bahasa pemograman java yang berjalan pada sistem operasi Linux Ubuntu, kemudian membangun cloud server menggunakan layanan Microsoft azure cloud service serta merancang dan membangun database untuk untuk aplikasi menggunakan MySQL dengan bahasa pemograman PHP diikuti dengan Web API yang dihasilkan dalam format JSON.

\subsection{Customer Test-Drives Mock-Up}

Pada tahap ini dilakukan evaluasi dari prototipe yang telah dibuat dengan cara melakukan pengujian. Pengujian dilakukan pada dua aplikasi, yaitu aplikasi pada smartphone anak berfungsi sebagai sender untuk mendapatkan history browser yang kemudian akan dikirim ke server database dan aplikasi pada ponsel orang tua berfungsi sebagai receiver yang nantinya 
akan menjadi sebuah sistem aplikasi dengan kemampuan mampu memonitoring aktivitas browsing internet ponsel anak dari ponsel orang tua. Pengujian aplikasi ini bertujuan untuk memastikan bahwa kinerja dari sistem dapat berfungsi sesuai yang diharapkan.

\section{Hasil dan Pembahasan}

Penelitian ini diharapkan dapat memudahkan orang tua untuk mendapatkan informasi tentang apa saja diakses anak pada saat melalakukan browsing internet pada ponsel yang dimiliki dan bermanfaat bagi orang tua untuk mengontrol anak jika anak mencoba melakukan aktivitas browsing internet yang tidak sehat.

Berikut hasil desain prototipe sistem untuk monitoring browser ponsel anak, dapat dilihat pada Gambar 5.

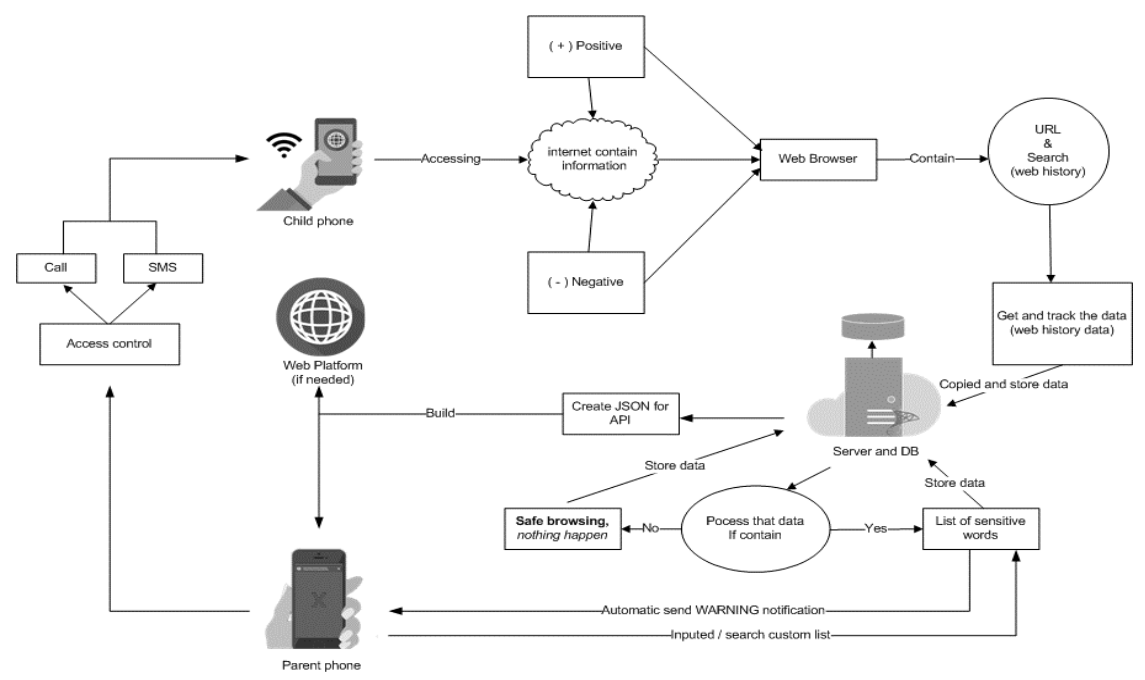

\section{Gambar 5. Hasil desain Prototipe aplikasi sistem monitoring browser ponsel anak}

Gambar 5 tentang sistem aplikasi monitoring browser ponsel anak yang terdiri dari fungsi, yaitu sender (smartphone anak) dan receiver (smartphone orang tua). Ketika anak melakukan browsing internet melalui web browser, data history internet anak secara otomatis akan tersimpan dalam smartphone sehingga data tersebut perlu di ambil kemudian dikirim ke server database. Sementara itu, didalam server database dibangun tempat penyimpanan daftar kata-kata sensitif berbau negatif yang nantinya daftar kata-kata tersebut digunakan untuk proses filter terhadap kata-kata kunci dari history yang telah diakses oleh anak. Jika pada proses filter history browser terdapat kata kunci yang berbau negatif, hasil dari proses filter akan memberikan notifikasi yang dikirim ke ponsel orang tua untuk menginformasikan bahwa anak mereka sedang mencoba melakukan browsing dengan kata kunci yang tidak baik. Dari notifikasi tersebut orang tua dapat memberikan respon, seperti:

1. Memberikan peringatan melalui SMS

2. Menghubungi anak melalui telepon

3. Melihat apa-apa saja yang anak mereka akses.

\section{Kesimpulan}

Sistem monitoring browser ponsel anak merupakan sebuah aplikasi monitoring pada perangkat mobile yang dapat melacak setiap aktivitas browsing internet yang dilakukan anakanak sampai dengan orang dewasa dengan bebas mengakses internet. informasi yang ditawarkan internet tersedia dalam banyak konten, mulai dari konten yang bersifat baik maupun kontek 
yang bersifat tidak baik atau negatif. Berdasarkan hasil survei pengguna internet Indonesia didominasi oleh anak-anak dan remaja yang menggunakan smartphone mereka untuk mengakses internet baik untuk mencari data atau informasi seperti tugas sekolah, sosial media, forum, dan sebagainya yang belum tentu informasi tersebut sesuai dan aman untuk anak dan remaja. Untuk itu, perlu dibuat sebuah desain aplikasi sistem monitoring browser ponsel anak untuk menerapkan internet sehat dengan kontrol orang tua dengan menggunakan metode prototipe berbasis android. aplikasi tersebut berguna bagi orang tua dalam membantu pengawasan terhadap anak dalam melakukan browser yang dianggap tidak baik, kemudian aplikasi tersebut dapat secara otomatis mengirim pesan notifikasi dan respon atau balasan secara langsung kepada orang tua ketika anak sedang mencoba melakukan aktivitas browsing internet yang tidak sehat.

\section{Daftar Pustaka}

[1] APIJII, 2016, Penetrasi \& Perilaku Pengguna Internet Indonesia, Indonesia Internet Service Provider Association.

[2] Astuti, S. D., Putri, I. P., \& Ali, D. S. F. (2017). Strategi Komunikasi Program Internet Sehat Dan Aman Kementerian Komunikasi Dan Informatika Republik Indonesia (Studi Kasus Evaluasi Program Incakap Tahun 2015. Jurnal Komunikasi, 8(1), 25-35.

[3] Jagtap, N. P., Patil, K. A., Shakil, S. S., dan Ingle, N. S. 2015, Mobile Activity Monitoring System Using Android Spy. International Journal of Advanced Research in Computer and Communication Engineering. Vol. 4(2): 2278-1021.

[4] Kathleen, A.E., Christoper, R.H., dan Elizabeth, H. 2016. The Longitudinal Impact of Perceptions of Parental Monitoring on Adolescent Initiation of Sexual Activity. Journal of Adolescent Healt. Vol. 59(5): 570-576.

[5] Kemp, S., 2016, 2016 Digital Yearbook, We are social.

[6] Kosidin dan Resha, N.F. 2016. Pemodelan Aplikasi Reminder Berbasis Android. Seminar Nasional Teknologi Informasi dan Komunikasi 2016 (SENTIKA 2016). 2089-9815.

[7] Novandya, A., Kartika, A., Wibowo, A., \& Libriadiany, Y. 2012. Aplikasi Pengenalan Budaya dari 33 Provinsi di Indonesia Berbasis Android. Prosiding KOMMIT Vol. 7.

[8] Mansur dan Kasmawi, 2017. Pengembangan Sistem Database Terpadu Berbasis Web Untuk Penyediaan Layanan Informasi Website Desa, Jurnal TEKNOSI, Vol. 03, No 1, April.

[9] Pressman, Roger. S. 2001. Software Engineering a Practitioner's Approach 5th ed. Mc Graww Hills.

[10] Purnomo, R. S., Handojo, A., dan Purbowo, A. N, 2016, Aplikasi TRUST (The Recording Unit of Spy Tools) pada Android. Jurnal Infra, 4(2), 142-148.

[11] Silva, P., Amorim, V. J., Ribeiro, F. N., dan Muzetti, I., 2015, PrivacyMod: Controlling and Monitoring Abuse of Privacy-Related Data by Android Applications. In 2015 Brazilian Symposium on Computing Systems Engineering (SBESC) (pp. 42-47). IEEE. 